\title{
Optimization and Prediction of Design Variables Driven by Building Energy Performance-A Case Study of Office Building in Wuhan
}

\author{
Jingyi Li ${ }^{(\bowtie)}$ and Hong Chen ${ }^{(\bowtie)}$ \\ Huazhong University of Science and Technology, Luoyu Road, Wuhan 1037, China \\ \{jimmylee, chhwh\} @hust.edu.cn
}

\begin{abstract}
This research focuses on the energy performance of office building in Wuhan. The research explored and predicted the optimal solution of design variables by Multi-Island Genetic Algorithm (MIGA) and RBF Artificial neural networks (RBF-ANNs). Research analyzed the cluster centers of design variable by K-means cluster method. In the study, the RBF-ANNs model was established by 1,000 simulation cases. The RMSE (root mean square error) of the RBF-ANNs model in different energy aspects does not exceed $15 \%$. Comparing to the reference case (the largest energy consumption case in the optimization), the 214 elite cases in RBF-ANNs model save at least 37.5\% energy. By the cluster centers of the design variables in the elite cases, the study summarized the benchmark of 14 design variables and also suggested a building energy guidance for Wuhan office building design.
\end{abstract}

Keywords: Building energy performance optimization - Parametric analysis · MIGA optimization · RBF artificial neural network model $\cdot$ K-means cluster analysis $\cdot$ EnergyPlus simulation

\section{Introduction}

As a new design method, the parametric design method has achieved considerable development in recent years [1,2]. More and more researcher pay attention on the parametric optimization of buildings based on building energy performance in recent years. Tuhus-Dubrow [3] studied the building energy consumption through different climatic conditions and different types of variables. He also studied the genetic algorithm for different building types and variables. By genetic algorithm research, it is found that the rectangular building plane and the trapezoidal building plane have the lowest cycle energy consumption under the five different climatic conditions. Gou [4] and Bre [5] did the sensitivity analysis of the variables in building energy optimization respectively. Jin [6] optimized the energy consumption level of a free-form building with few constraints. Zhang [7] optimized the energy efficiency of the specific classroom type of the school classroom, and different types of classrooms were set as discrete variables. 
In 1943, McCulloch and Pitts established the first artificial neural networks model (ANNs-model). In the 1980s, Hopfield successfully applied ANNs-model to the optimization problems. Today, the ANNs technology have been widely used in function approximation, expert systems, artificial intelligence, and optimization problems [8].

Recent studies have shown that research on building energy performance based on ANNs technology can achieve outstanding results [9-11]. Among them, in the field of building energy performance, Zemella [9] used ANNs-model to optimize building façades. Ayata [11] used the ANNs technology to predict the natural ventilation of buildings.

\section{Research Method}

\subsection{Research Objectives}

The research objective is to improve the overall energy performance level of office buildings in Wuhan during the operation phase, so the research objective is to minimize $E_{A}$. The unit is $\mathrm{kw} \cdot \mathrm{h} / \mathrm{m}^{2}$.

The total annual energy consumption $\left(E_{A}\right)$ of office buildings is included: 1 . annual energy consumption of building cooling system $\left(E_{C}\right)$, 2. annual energy consumption of building heating system $\left(E_{H}\right), 3$. annual energy consumption of building lighting system $\left(E_{L}\right), 4$. annual energy consumption of building electronic equipment $\left(E_{E}\right)$. This study will calculate $E_{A}$ through 8760 simulation iteration. Because the electronic equipment in office buildings is mainly computers, the turning on and off is only related to the schedule of users. Therefore, it is hardly to change $E_{E}$ by changing the design variables. $E_{A}$ of the office building in this research is obtained by Eq. 1.

$$
E_{A}=E_{C}+E_{H}+E_{L}
$$

The integral electric drive chiller has been chosen as the cooling source equipment of the air conditioning system in this study. Its performance coefficient $\left(S C O P_{T}\right)$ follow the "Design Standard for energy efficiency of public buildings GB50189-2015" and is set as 2.50. $A$ is the total floor area of the building. The annual cooling energy consumption $E_{C}$ is obtained by Eq. 2, and the annual cumulative cooling power consumption $\left(Q_{C}\right)$ is the simulation result by EnergyPlus.

$$
E_{C}=\frac{Q_{C}}{A * S C O P_{T}}
$$

The gas boiler has been chosen as the heat source equipment for the heating system in this study. According to the "Design Standard for energy efficiency of public buildings GB50189-2015", the overall efficiency of the heating system $\left(\eta_{2}\right)$ was set to 0.75 and the coal consumption for power generation $\left(q_{2}\right)$ is $0.36 \mathrm{kgce} / \mathrm{kWh}$, the standard natural gas value $\left(q_{3}\right)$ is set to $9.87 \mathrm{kWh} / \mathrm{m}^{3}$, and the conversion coefficient $(\phi)$ of natural gas and standard coal was set to $1.21 \mathrm{kgce} / \mathrm{m}^{3}$. A is the total floor area of the building. The annual heating energy consumption $E_{H}$ can be obtained by Eq. 3, and the annual cumulative heating power consumption $\left(Q_{H}\right)$ is the simulation result by EnergyPlus.

$$
E_{H}=\frac{Q_{H}}{A * \eta_{2} q_{3} q_{2}} \phi
$$


The open-type luminaires have been chosen as the indoor lighting system in this study. According to the "Standard for lighting design of buildings GB 50034-2013", its efficiency $(\eta P)$ was set to 0.75 . $A$ is the total floor area of the building. The annual lighting energy consumption $E_{L}$ can be obtained by Eq. 4, and the annual cumulative lighting power $\left(Q_{L}\right)$ is the simulation result by EnergyPlus.

$$
E_{L}=\frac{Q_{L}}{A * \eta_{P}}
$$

\subsection{Research Method}

This study focuses on the effects of different design variables on $E_{A}$ of office building in Wuhan. The study first established a parametric platform between design variables and building energy simulation software. An approximate model is established by the RBF-ANNs technology. The approximate model is optimized by the MIGA algorithm to search the elite cases of design variables. The research analyzed the elite cases of the design variables in the optimization. By K-means cluster analysis of the elite cases, the study could locate the optimal benchmark of each variable.

The energy simulation software used in this study is EnergyPlus 8.1.2. Because this study is aimed at the annual energy consumption of office buildings, the study not only needs to set up a simulation model, but also needs to set the schedule of office buildings. According to "Design Standard for Energy Efficiency of Public Buildings (GB50189-2015)", the research set the annual cooling and heating system schedule, the annual building occupancy schedule and annual ventilation system schedule. The annual interior lighting system schedule needs to be adjusted based on the natural daylight conditions. DaySim software is used to simulate the natural daylight conditions and the annual interior lighting system schedule has been set followed the DaySim simulation result $[2,13]$.

\subsection{Multi-Island Genetic Algorithm (MIGA) and Radial Basis Functions Artificial Neural Networks (RBF-ANNs)}

The variable combination optimization method used in this research is Multi-Island Genetic Algorithm (MIGA). Multi-island Genetic Algorithm (MIGA) is an improved standard genetic algorithm (SGA) [14]. Details of the MIGA algorithm settings in this study are shown in Table 1.

As an approach to reduce the complexity of the model and improve the computational efficiency, the approximate modeling method is used by more and more researchers [10, 11]. ANNs as a popular approximate modeling method, has advantages in solving highly complex function problems. ANNs is similar to biological nervous system and consist of layers of parallel basic units (called neurons) [8]. Neurons are connected to each other by a large number of weighted links through which information can enter the entire system. Basically, a neuron receives input information into ANNs' input layer, merges the input information, performs non-linear operations in the Radial basis functions layer, and then output layer gives the final result (Fig. 1). RBF (Radial Basis Functions) ANNs is used 
in this research, which is one of the most commonly used artificial neural networks [10]. Details of the RBF-ANNs model settings in this study are shown in the Table 2.

The research found that the shortcomings of the RBF-ANNs are obvious: 1 . When the sampling data is insufficient, the RBF-ANNs will not be able to run; 2. Because of the nonlinear mapping ability of the RBF-ANNs is determined by its basis functions and the characteristics of the basis function are mainly determined by the center of the basis function, it is difficult to reach high precision by randomly selecting points as the center points to build the RBF-ANNs model.

This study will use the random sampling (RS) and Latin hypercube sampling (LHS) methods [8] to set the variables. Then use RBF-ANNs technology to establish different approximation models based on the simulation results. Finally, the MIGA is used to optimize the design variables with the best RBF-ANNs approximate model.

At the same time, the study will use testing group to analyze the prediction error of different RBF-ANNs models [15]. The study will use the Root Mean Square Error (RMSE) method to compare the RBF-ANNs' prediction results and the simulation results of the testing group. In this study, the accuracy threshold of the RMSE value is $15 \%$.

$$
R M S E=\sqrt{\frac{1}{N} \sum_{t=1}^{N}\left(D_{t}^{O}-D_{t}^{P}\right)^{2}}
$$

Table 1. MIGA algorithm setting

\begin{tabular}{l|l|l|l}
\hline Related parameters & Value & Related parameters & Value \\
\hline Sub-population size & 10 & Interval of migration & 5 \\
\hline Number of Island & 10 & Elite size & 1 \\
\hline Number of generations & 50 & Rel tournament size & 0.5 \\
\hline Rate of crossover & 0.9 & Penalty base & 0.0 \\
\hline Rate of mutation & 0.02 & Penalty multiplier & 1000.0 \\
\hline Rate of migration & 0.2 & Penalty exponent & 2 \\
\hline & & Default variable bound (abs val) & 1000.0 \\
\hline
\end{tabular}

\section{Research Setting}

Because of the complexity of building system, researcher needs to search the design variables which have highly correlation with building energy performance. From the reference [3, 15-17], the study found that the four aspects of the design variables have a high correlation with building energy performance: 1 . building plan (BP), 2. window shape (WS), 3. building orientation (BO), 4. building insulation thickness (BIT), 5 . horizontal visor (HV) (Fig. 2). 

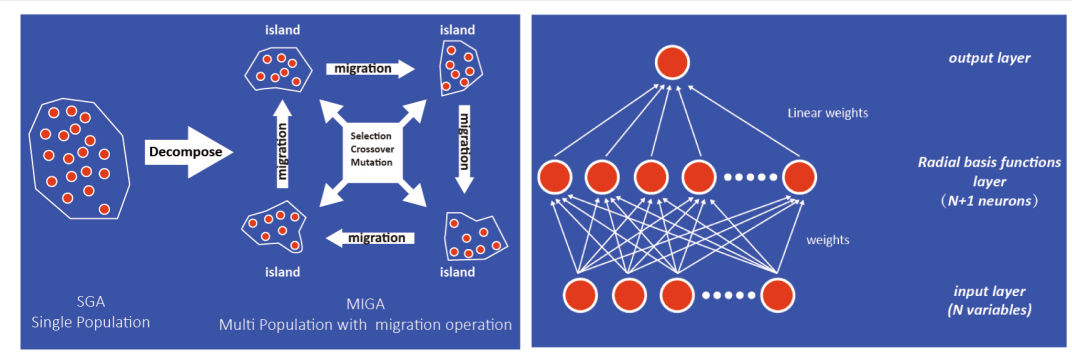

Fig. 1. Schematic diagram for the MIGA (left) RBF-ANNs workflow chart (right)

Table 2. RBF-ANNs setting

\begin{tabular}{l|l|l|l|l}
\hline $\begin{array}{l}\text { Related } \\
\text { parameters }\end{array}$ & Model A & Model B & Model C & Model D \\
\hline $\begin{array}{l}\text { Smoothing } \\
\text { filter }\end{array}$ & 0.00 & 0.00 & 0.00 & 0.00 \\
\hline Basis function & Radial & Radial & Radial & Radial \\
\hline Iterations to fit & 50 & 50 & 50 & 50 \\
\hline $\begin{array}{l}\text { Sampling } \\
\text { method }\end{array}$ & $\begin{array}{l}\text { Random }(250 \\
\text { points) }\end{array}$ & $\begin{array}{l}\text { Random }(500 \\
\text { points })\end{array}$ & $\begin{array}{l}\text { Latin Hypercube } \\
(500 \text { points })\end{array}$ & $\begin{array}{l}\text { Latin Hypercube } \\
\text { (1000 points) }\end{array}$ \\
\hline $\begin{array}{l}\text { Sampling } \\
\text { optimize time } \\
\text { (minute) }\end{array}$ & 0 & 0 & 5 & 10 \\
\hline $\begin{array}{l}\text { Error analysis } \\
\text { sampling } \\
\text { method }\end{array}$ & $\begin{array}{l}\text { Random } 150 \\
\text { points }\end{array}$ & $\begin{array}{l}\text { Random 150 } \\
\text { points }\end{array}$ & $\begin{array}{l}\text { Random 150 } \\
\text { points }\end{array}$ & $\begin{array}{l}\text { Random 150 } \\
\text { points }\end{array}$ \\
\hline $\begin{array}{l}\text { Approximation } \\
\text { improvement } \\
\text { method }\end{array}$ & $\begin{array}{l}\text { Sequential } \\
\text { sampling method }\end{array}$ & $\begin{array}{l}\text { Sequential } \\
\text { sampling method }\end{array}$ & $\begin{array}{l}\text { Sequential } \\
\text { sampling method }\end{array}$ & $\begin{array}{l}\text { Sequential } \\
\text { sampling method }\end{array}$ \\
\hline
\end{tabular}

In terms of BP, this research focused on the values of the building plane aspect ratio (A) and floor height $(\mathrm{H})$. Among them, A controls the planar shape of the building, and $\mathrm{H}$ controls the height of the building.

In terms of WS, this study focused on the size of windows in different orientations. The design variables are window to wall ratio (WWR) on north direction (WWR-N), WWR on east direction (WWR-E), WWR on south direction (WWR-S), WWR on west direction (WWR-W) and the window height (WH).

In terms of $\mathrm{BO}$, this study focused on the angle $(\mathrm{O})$ between the $\mathrm{X}$ axis of the building plane and the East direction of the simulation software ( $X$ axis of the 3D model software).

In terms of BIT, this study focused on the roof insulation thickness (RT) and the wall insulation thickness (WT). 


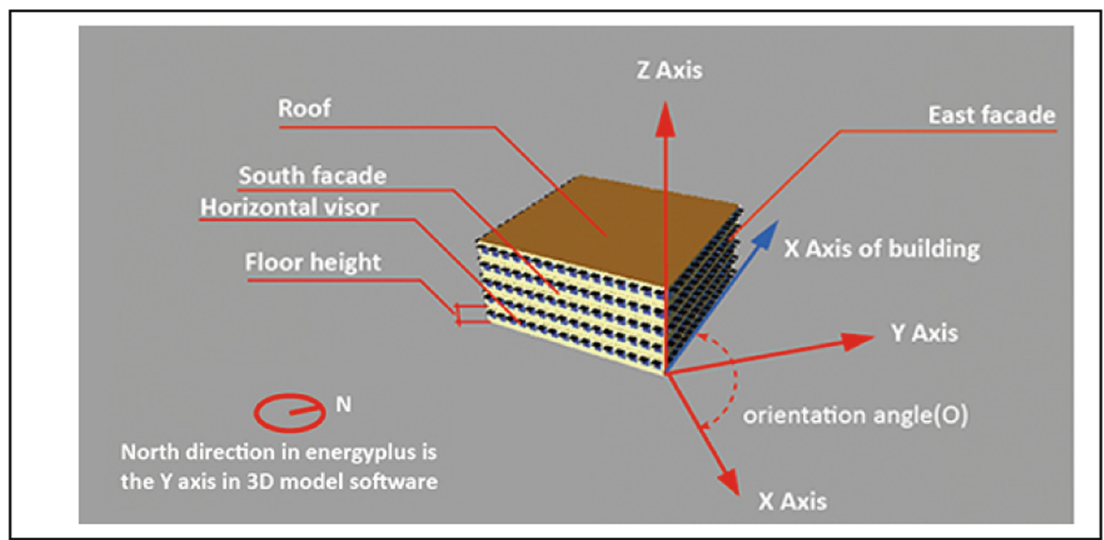

Fig. 2. The office building model in $3 \mathrm{D}$ model software

In terms of $\mathrm{HV}$, this study set four variables for the external visors in four directions. The variables are the length of the external horizontal visors in north direction (HV$\mathrm{N}$ ), the length of the external horizontal visors in west direction (HV-W), the length of the external horizontal visors in south direction (HV-S) and the length of the external horizontal visors in east direction (HV-E).

The detailed of the design variables of the office building is shown in the Table 3.

Table 3. The design variables

\begin{tabular}{|c|c|c|c|c|}
\hline \multicolumn{2}{|c|}{ The name of design variable } & Nomenclature & The range & Unit \\
\hline \multicolumn{2}{|c|}{ Building plane aspect ratio } & A & 1.2 to 5.0 & None \\
\hline \multicolumn{2}{|l|}{ Floor height } & $\mathrm{H}$ & 3.00 to 5.00 & Meter \\
\hline \multicolumn{2}{|l|}{ Window height } & WH & 0.50 to 2.00 & Meter \\
\hline \multicolumn{2}{|l|}{ Building orientation } & $\mathrm{O}$ & -90 to 90 & Degree \\
\hline \multirow[t]{2}{*}{ Building insulation } & Roof insulation thickness & RT & 0.05 to 0.3 & \multirow[t]{2}{*}{ Meter } \\
\hline & Wall insulation thickness & WT & 0.05 to 0.3 & \\
\hline \multirow{4}{*}{$\begin{array}{l}\text { Window-Wall ratio } \\
\text { (WWR) }\end{array}$} & WWR on north direction & WWR-N & 0.20 to 0.80 & \multirow{4}{*}{ None } \\
\hline & WWR on west direction & WWR-W & 0.20 to 0.80 & \\
\hline & WWR on south direction & WWR-S & 0.20 to 0.80 & \\
\hline & WWR on east direction & WWR-E & 0.20 to 0.80 & \\
\hline \multirow{4}{*}{$\begin{array}{l}\text { Horizontal visor } \\
\text { (HV) }\end{array}$} & HV on north direction & $\mathrm{HV}-\mathrm{N}$ & 0.1 to 2.0 & \multirow[t]{4}{*}{ Meter } \\
\hline & $\mathrm{HV}$ on west direction & HV-W & 0.1 to 2.0 & \\
\hline & HV on south direction & $\mathrm{HV}-\mathrm{S}$ & 0.1 to 2.0 & \\
\hline & $\mathrm{HV}$ on east direction & HV-E & 0.1 to 2.0 & \\
\hline
\end{tabular}


This study mainly focused on the design variables could be used by the architects, the setting of other variables which have an impact on building energy performance are based on "Design Standard for Energy Efficiency of Public Buildings GB50189-2015", "Standard for lighting design of buildings GB50034-2013" and "Design standard for residential buildings of low energy consumption DB42T_559-2013". The information of the office building is listed as boundary condition in the Table 4. The construction materials are listed in the Appendix Table 6. The annual cooling and heating system schedule, annual occupancy rate schedule and annual ventilation system schedule are followed the design standard. The annual interior lighting system schedule has been set by DaySim simulation result $[12,13]$.

Table 4. The boundary setting of the energy simulation

\begin{tabular}{l|l|l}
\hline The setting name & Value & Unit \\
\hline The number of zone in every floor & 5 & None \\
\hline Num of people per area & 0.1 & $\mathrm{per} / \mathrm{m}^{2}$ \\
\hline Total floor area & 5000 & $\mathrm{~m}^{2}$ \\
\hline Building floors & 5 & None \\
\hline Equipment load per area & 15.00 & $\mathrm{~W} / \mathrm{m}^{2}$ \\
\hline Lighting density per area & 9.00 & $\mathrm{~W} / \mathrm{m}^{2}$ \\
\hline Infiltration rate per area & 0.0003 & $\mathrm{~m}^{3} / \mathrm{s} \mathrm{per} \mathrm{m}^{2}$ \\
\hline Ventilation per area & 0.001 & $\mathrm{~m}^{3} / \mathrm{s}$ per $\mathrm{m}^{2}$ \\
\hline Ventilation per person & 0.008 & $\mathrm{~m}^{3} / \mathrm{s} \mathrm{per} \mathrm{person}$ \\
\hline Recirculated air per area & 0 & $\mathrm{~m}^{3} / \mathrm{s}$ per $\mathrm{m}^{2}$ \\
\hline Lighting power & 250 & $\mathrm{~W}$ \\
\hline Lighting set point & 300 & $\mathrm{Lux}$ \\
\hline
\end{tabular}

\section{The RBF-ANNs Optimization Process}

\subsection{The Comparison of RBF-ANNs Models}

Before using RBF-ANNs model for the optimization process, it is necessary to check the RBF-ANNs models' accuracy. The accuracy of the RBF-ANNs model is related to the number of sampling points and the sampling method. The research set up 4 different RBF-ANNs models through different sampling numbers $(250,500,1000)$ and different sampling methods (RS and LHS method). Through a RMSE method analysis for the prediction results, the study found that:

- The accuracy of the RBF-ANNs model is very sensitive to the number of input values. Because only 250 variable combination values are randomly sampled at Model-A, The RMSE values in all aspects exceed the threshold (15\%). 
- The accuracy of the RBF-ANNs model is very sensitive to the sampling method. Because the sampling method in Model-B is random sampling and in Model-C is Latin Hyper-cube method, the RMSE values of Model-C is better than the value of Model-B. RMSE values of $E_{A}, E_{H}$, and $E_{L}$ in Model-B is $20.264 \%, 16.135 \%$, and $18.135 \%$, respectively. RMSE values of $E_{A}, E_{C}, E_{H}$, and $E_{L}$ in Model-C is $13.319 \%$, $9.208 \%, 9.28 \%$, and $12.799 \%$, respectively.

- By comparing the RMSE values between Model-C and Model-D, due to more sampling values in model-D (1000 values) than values in model-C (500 values), the RMSE value of model-D $\left(E_{A}, E_{H}, E_{L}\right.$ is $\left.12.132 \%, 7.503 \%, 11.829 \%\right)$ is better than RMSE value of model-C ( $E_{A}, E_{H}, E_{L}$ is $\left.13.319 \%, 9.28 \%, 12.799 \%\right)$ (Fig. 3).

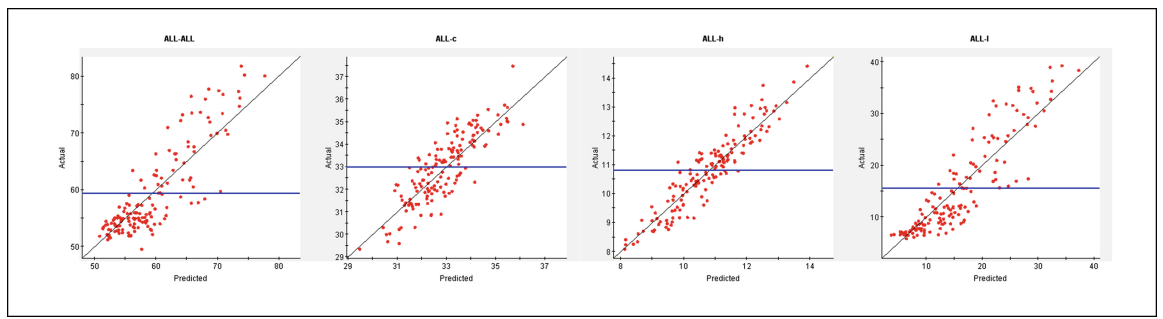

Fig. 3. Residual plots of prediction results and test values for $E_{A}, E_{C}, E_{H}$, and $E_{L}$ in model-D

\subsection{RBF-ANNs Optimization Process}

The research uses the selected RBF-ANNs model (model-D) as the basic model for optimization. The MIGA algorithm is used to optimize the design variables in the basic model. The MIGA algorithm settings are listed in Appendix Table 1. The optimization process of RBF-ANNs model took less than $10 \mathrm{~min}$. After 60 generations of optimization, the optimization results of the RBF-ANNs model have been stabilized (Fig. 4). The study found that the lowest value of $E_{A}$ can reach $46.44 \mathrm{~kW} \cdot \mathrm{h} / \mathrm{m}^{2}$.

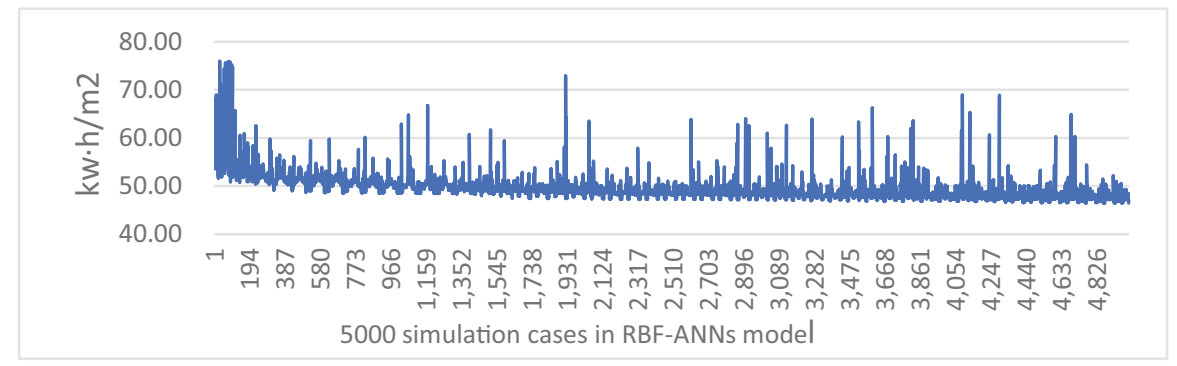

Fig. 4. The optimization history of $E_{A}$ by MIGA algorithm and the RBF-ANNs model

Since the single energy simulation takes nearly $10 \mathrm{~min}$, and the 100 generations MIGA optimization will perform 5000 energy simulation calculations, it will take 
approximately $833.33 \mathrm{~h}$ for the MIGA optimization. On the other hand, the optimization of the RBF-ANNs model is divided into three parts: 1. Establishing an approximate model through 1000 energy simulations (166.8 h); 2 . Testing the model by 150 energy simulations ( $25 \mathrm{~h}$ ) 3 . Optimization using the RBF-ANNs approximate model and MIGA algorithm $(0.08 \mathrm{~h})$. These three steps took approximately $191.88 \mathrm{~h}$. In terms of time consumption, compared with using MIGA algorithm alone, RBF-ANNs model optimization will save $76.97 \%$ of time. Therefore, in terms of efficiency, the RBF-ANNs model has great advantages $[8,9,11]$.

Before analyzing the variables benchmarks, the predicted value of the RBF-ANNs model needs to be tested. In this study, the 30 lowest $E_{A}$ variable combinations in RBF-ANNs model were extracted for testing.

After running the energy simulation for the 30 lowest $E_{A}$ variable combinations and comparing the predicted value with the actual simulation value, the study found that:

- The $E_{A}$ prediction value of RBF-ANNs model is lower than the simulation value, which indicates that there is a certain error between the prediction values and the simulation values. Despite the errors, the $E_{A}$ simulation values of these 30 variable combinations are all less than $52.0 \mathrm{kw} \cdot \mathrm{h} / \mathrm{m}^{2}$.

- Compared with the $E_{A}$ value of the Reference Case $\left(83.19 \mathrm{kw} \cdot \mathrm{h} / \mathrm{m}^{2}\right)$, the energy decline has reached at least $37.5 \%$. This shows that it is feasible to optimize building energy performance by the RBF-ANNs model [11]

- The $E_{C}$ prediction value of the RBF-ANNs model is consistent with the simulation value, which indicates that the prediction accuracy of the RBF-ANNs model in $E_{C}$ is high.

- The $E_{H}$ prediction value of the RBF-ANNs model is consistent with the simulation value, which indicates that the prediction accuracy of the RBF-ANNs model in $E_{H}$ is high.

- The $E_{L}$ prediction value of the RBF-ANNs model is significantly different from the simulation value. Due to the simulation of $E_{C}$ and $E_{H}$ does not take into account the changing schedule, the RBF-ANNs model can well establish the nonlinear equations between the variables and the simulation results. On the other hand, since the $E_{L}$ simulation needs to consider the effect of natural daylight on the annual interior lighting system schedule, there is a more complicated nonlinear relationship between the variables and the $E_{L}$ simulation results. This complex relationship is the main reason for the low accuracy of the RBF-ANNs model $E_{L}$ prediction (Fig. 5).

\subsection{Analysis the Optimization Results}

Prior to analysis the benchmark of variable values, the study screened the optimization results. The study selected $47.0 \mathrm{kw} \cdot \mathrm{h} / \mathrm{m}^{2}$ as the $E_{A}$ threshold value for the screening process. the study found that 214 cases in the RBF-ANNs model optimization process met the screening requirements, and these cases will become the elite cases for k-means cluster analysis. The research found that the cases that met the requirements were mainly concentrated after the 80th generation. This proved that the optimization combined MIGA with the RBF-ANNs model for the office building energy performance was successful. 


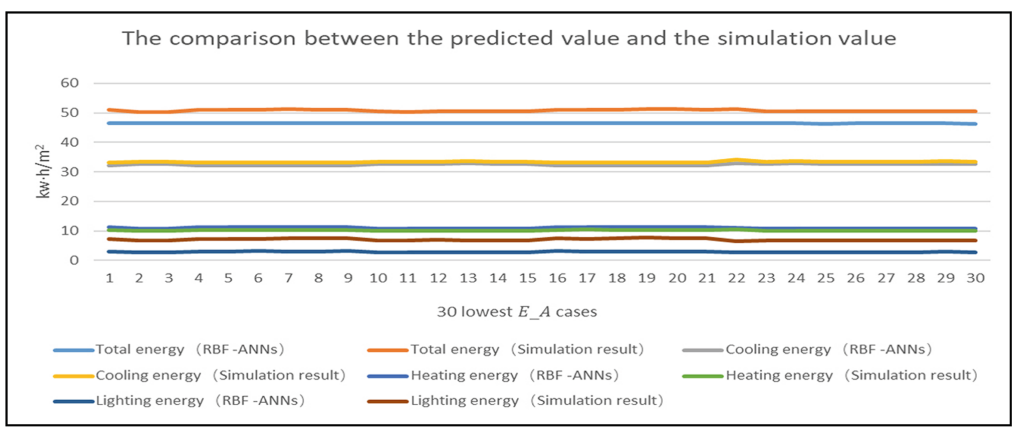

Fig. 5. Comparison of $30 \mathrm{RBF}-\mathrm{ANNs}$ model prediction values and simulation values

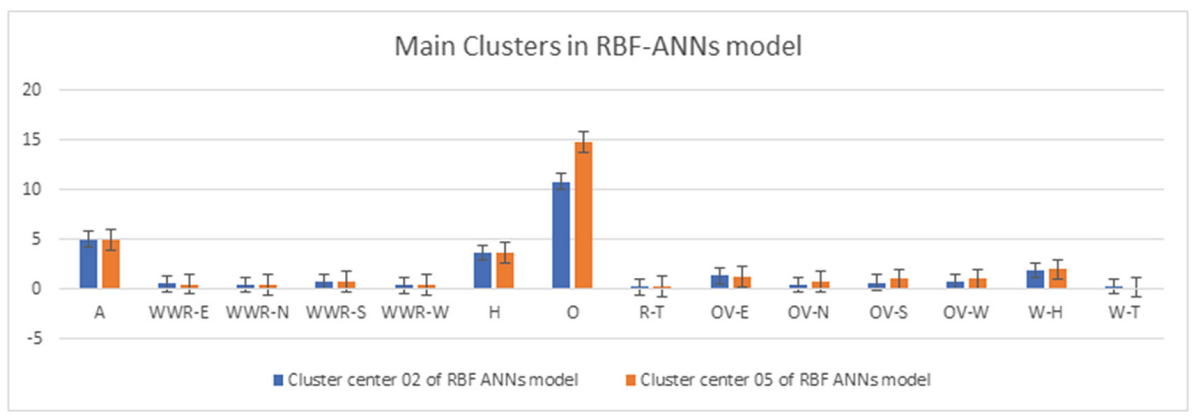

Fig. 6. Comparison chart of each design variable cluster centers

The study compared the different energy aspects of the elite cases in the MIGA optimization process and found that the proportions of different energy aspects in the elite cases are roughly same. The proportion is consistent with the high temperature and high humidity climate in Wuhan summer [18]. Due to the largest proportion in $E_{A}$ is $E_{C}$, it is found that the most effective way to improve office building energy performance in Wuhan is to reduce $E_{C}$.

\subsection{K-means Cluster Analysis}

Clustering is a machine learning technique that is considered to be one of the most effective data mining processes and the most commonly used algorithm for building energy analysis is K-means clustering [19]. The K-means clustering would be used in this research for finding the benchmarks of variables (Fig. 6).

The study sets the number of clusters in K-means clustering analysis to 5 separately for the optimization. From Table 5, the study found that cluster 2 in RBF-ANNs cluster analysis has 118 elite cases, and cluster 5 has 70 . These two clusters account for $87.8 \%$ of all elite cases in RBF-ANNs model optimization. It means that the value of each design variable in these two clusters represents the benchmarks of each design variable in RBF-ANNs model optimization. 
Table 5. The final cluster centers for the elite cases

\begin{tabular}{l|c|c|c|c|c}
\hline K-means cluster analysis & Cluster 01 & Cluster 02 & Cluster 03 & Cluster 04 & Cluster 05 \\
\hline Variables & 4.745 & 4.981 & 4.985 & 4.725 & 4.925 \\
\hline A & .569 & .526 & .524 & .579 & .499 \\
\hline WWR-E & .449 & .434 & .435 & .451 & .436 \\
\hline WWR-N & .775 & .742 & .733 & .788 & .796 \\
\hline WWR-S & .407 & .375 & .376 & .373 & .370 \\
\hline WWR-W & 3.718 & 3.667 & 3.649 & 3.723 & 3.685 \\
\hline H & 8.266 & 10.804 & 34.208 & 5.958 & 14.790 \\
\hline O & .140 & .201 & .200 & .132 & .218 \\
\hline RT & .879 & 1.365 & 1.353 & .844 & 1.182 \\
\hline HV-E & .346 & .429 & .417 & .327 & .694 \\
\hline HV-N & .961 & .659 & .683 & .947 & 1.006 \\
\hline HV-S & .529 & .729 & .742 & .633 & .999 \\
\hline HV-W & 1.889 & 1.866 & 1.909 & 1.825 & 1.974 \\
\hline WH & .246 & .246 & .194 & .239 & .287 \\
\hline WT & 11.000 & 118.000 & 4.000 & 11.000 & 70.000 \\
\hline Number of observations in each cluster & 214000 & & & & \\
\hline Effective & .000 & & & &
\end{tabular}

\section{The Conclusion}

The research chooses the cluster centers in the RBF-ANNs optimization as the benchmarks. The study found that:

In terms of building aspect ratio, due to the large proportion of $E_{L}$ in $E_{A}$ and great optimization potential for $E_{L}$, the study found that the north-south facade of the building should be as long as possible,, which will help the sun enter into the building. Since the value range of $\mathrm{A}$ in this study is 1.2 to 5.0, the study believes that within this range, the north-south facade can be as long as possible.

In terms of building height, as the increase of $\mathrm{H}$ will increase the building volume, which will increase $E_{C}$ and $E_{H}$, the building floor height should be as small as possible in an acceptable range.

In terms of building orientation, due to the large proportion of $E_{L}$ in $E_{A}$ and great optimization potential for $E_{L}$, the value of $O$ should be considered how to increase the length of the south-facing facade as much as possible. When the value of $\mathrm{A}$ is about 4.9 and $\mathrm{O}$ is between $10^{\circ}$ and $14^{\circ}$, the diagonal of the building rectangle will be perpendicular to the south direction, so that the length of the south facade will be the largest. This would let more natural light enter into the building, and $E_{L}$ would be the smallest.

In terms of the thickness of the building insulation, the research found that the thickness of the roof insulation is between 0.20 and 0.22 , and the thickness of the wall insulation is between 0.25 and 0.28 . Although the maximum value in the variable range has not been taken, the two thickness have high values.

In terms of WWR, the study found that the value of WWR-W is the smallest and should not exceed 0.4, the value of WWR-N and WWR-E should not be greater than 0.5, and the value of WWR-S is the largest and should not below 0.7. In general, the WWR of 


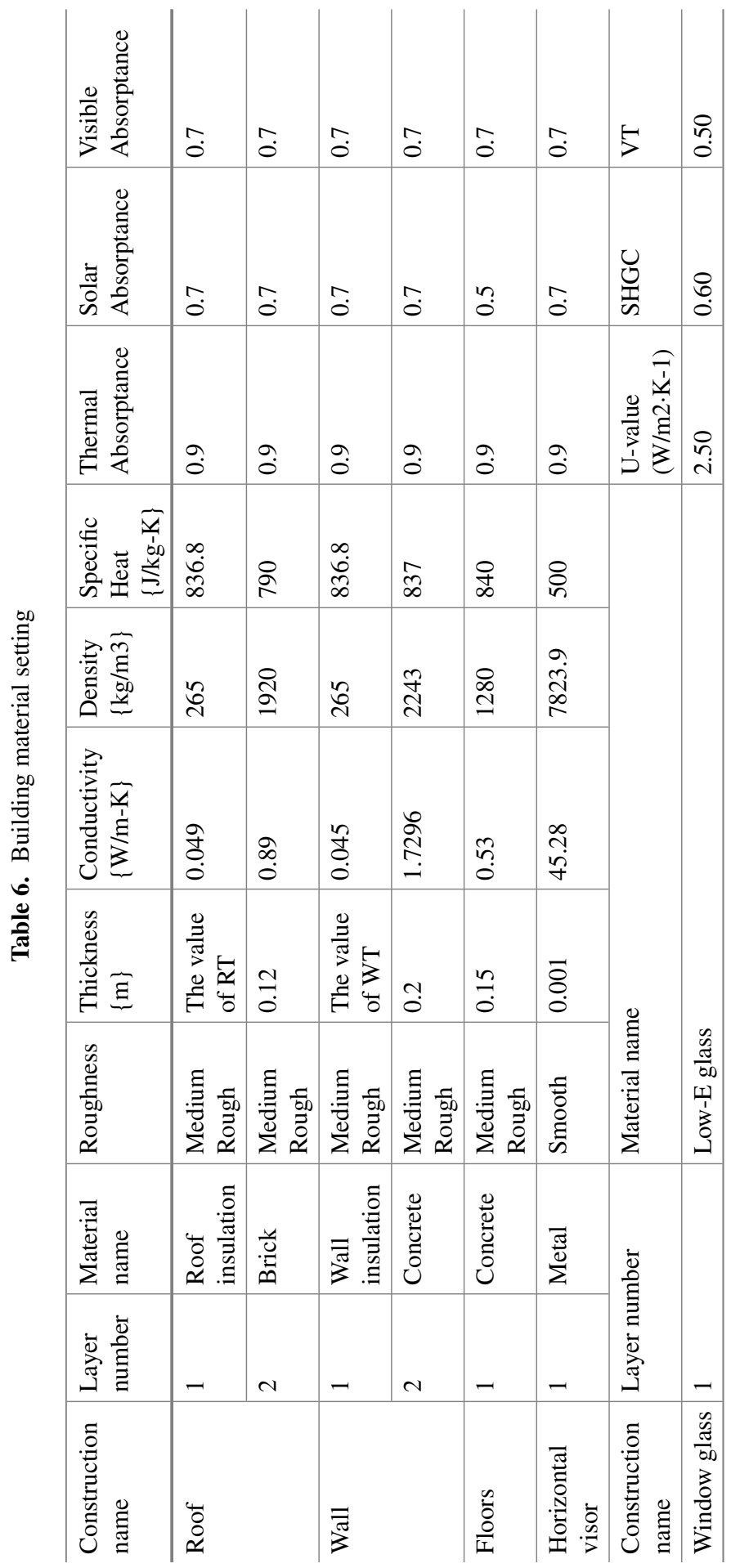


office buildings in Wuhan should consider façade direction. The value of WWR should be small in all directions except south façade.

In terms of building window height, the study found that the value is about $1.8 \mathrm{~m}$. This shows that the building needs a high window height. Because the WWR value in west and east is generally low, a higher W-H value will make the building's east-west window opening style be high and narrow, which will help east-west shading.

In terms of $\mathrm{HV}$, the research found that the value of HV-N is the smallest, and should not exceed $0.7 \mathrm{~m}$. This is because there is no natural light from the north direction, so it is not necessary to block sunlight by a long visor. Due to the east-west window opening style is high and narrow, there is no need too much horizontal visor for shading, so the value of HV-W is between $0.7 \mathrm{~m}$ to $1.0 \mathrm{~m}$. Due to the value of WWR-E is about 0.5 , larger than the value of WWR-W, the value of HV-E is larger than the value of $\mathrm{HV}-\mathrm{W}$, is between $1.2 \mathrm{~m}$ to $1.4 \mathrm{~m}$. Although the WWR-S value is larger than 0.7 , due to the large proportion of $E_{L}$ in $E_{A}$ and great optimization potential for $E_{L}$, the value of HV-S is not too large, is between $0.7 \mathrm{~m}$ to $1.0 \mathrm{~m}$.

\section{References}

1. Turrin, M., Von Buelow, P., Stouffs, R.: Design explorations of performance driven geometry in architectural design using parametric modeling and genetic algorithms. Adv. Eng. Inform. 25, 656-675 (2011)

2. Wang, L., Wong Nyuk, H., Li, S.: Facade design optimization for naturally ventilated residential buildings in Singapore. Energy Build. 39(8), 954-961 (2007)

3. Tuhus-Dubrow, D., Krarti, M.: Genetic-algorithm based approach to optimize building envelope design for residential buildings. Build. Environ. 45, 1574-1581 (2010)

4. Gou, S., Nik, V.M., Scartezzini, J.-L., Zhao, Q., Li, Z.: Passive design optimization of newlybuilt residential buildings in Shanghai for improving indoor thermal comfort while reducing building energy demand. Energy Build. 169, 484-506 (2018)

5. Bre, F., Silva, A.S., Ghisi, E., Fachinotti, V.D.: Residential building design optimisation using sensitivity analysis and genetic algorithm. Energy Build. 133, 853-866 (2016)

6. Jin, J.-T., Jeong, J.-W.: Optimization of a free-form building shape to minimize external thermal load using genetic algorithm. Energy Build. 85, 473-482 (2014)

7. Zhang, A., Bokel, R., Dobbelsteen, A., Sun, Y., Huang, Q., Zhang, Q.: Optimization of thermal and daylight performance of school buildings based on a multi-objective genetic algorithm in the cold climate of China. Energy Build. 139 (2017)

8. Magnier, L., Haghighat, F.: Multiobjective optimization of building design using TRNSYS simulations, genetic algorithm, and Artificial Neural Network. Build. Environ. 45, 739-746 (2010)

9. Zemella, G., De March, D., Borrotti, M., Poli, I.: Optimised design of energy efficient building façades via Evolutionary Neural Networks. Energy Build. 43, 3297-3302 (2011)

10. Cheng, M.-Y., Cao, M.-T.: Accurately predicting building energy performance using evolutionary multivariate adaptive regression splines. Appl. Soft Comput. 22, 178-188 (2014)

11. Ayata, T., Arcaklioglu, E., Yildiz, O.: Application of ANN to explore the potential use of natural ventilation in buildings in Turkey. Appl. Therm. Eng. 27, 12-20 (2007)

12. Yun, G., Kim, K.: An empirical validation of lighting energy consumption using the integrated simulation method. Energy Build. 57, 144-154 (2013)

13. Manzan, M., Pinto, F.: Genetic optimization of external shading devices. Energy Build. 72 (2009) 
14. Wang, F.P., Xu, Y., Zhang, G.Q., Zhang, K.: Aerodynamic optimal design for a glider with the supersonic airfoil based on the hybrid MIGA-SA method. Aerosp. Sci. Technol. 92, 224-231 (2019)

15. Krarti, M., Ouarghi, R.: Building shape optimization using neural network and genetic algorithm approach. ASHRAE Trans. 112 (2006)

16. Wang, W., Rivard, H., Zmeureanu, R.: Floor shape optimization for green building design. Adv. Eng. Inform. 20(4), 363-378 (2006)

17. Wright, J., Mourshed, M.: Geometric optimization of fenestration (2009)

18. Ichinose, T., Lei, L., Lin, Y.: Impacts of shading effect from nearby buildings on heating and cooling energy consumption in hot summer and cold winter zone of China. Energy Build. 136, 199-210 (2017)

19. Borgstein, E.H., Lamberts, R., Hensen, J.L.M.: Evaluating energy performance in nondomestic buildings: a review. Energy Build. 128, 734-755 (2016)

Open Access This chapter is licensed under the terms of the Creative Commons Attribution 4.0 International License (http://creativecommons.org/licenses/by/4.0/), which permits use, sharing, adaptation, distribution and reproduction in any medium or format, as long as you give appropriate credit to the original author(s) and the source, provide a link to the Creative Commons license and indicate if changes were made.

The images or other third party material in this chapter are included in the chapter's Creative Commons license, unless indicated otherwise in a credit line to the material. If material is not included in the chapter's Creative Commons license and your intended use is not permitted by statutory regulation or exceeds the permitted use, you will need to obtain permission directly from the copyright holder.

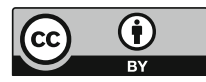

